\title{
Uncontrolled Asthma is Associated with Comorbid Stress and Somatoform Symptoms
}

\author{
Matthew Moore, $B S^{1}, C$ Dash Duncan, $B S^{1}$, Antigone Gonis, $M D^{1}$, Charlotte Chaiklin, $M D^{1}$, \\ David Eckles, $B A^{1}$ and Nereida A Parada, $M D^{2 *}$
}

${ }^{1}$ Tulane University School of Medicine, New Orleans, LA, USA

${ }^{2} J o h n$ W. Demming Department of Medicine, Section of Pulmonary Disease, Critical Care, and Environmental Medicine, Tulane University, New Orleans, LA, USA

\begin{abstract}
Background: Anxiety and depression are recognized comorbidities that may limit control of asthma. The purpose of this study is to identify the associations between perceived stress, somatization, and perceived asthma control in patients with asthma.

Methods: The present study included 100 adult outpatients who were treated at the Tulane Asthma Center for asthmarelated symptoms between March 2018 and November 2018. Patients were asked to complete a 3-item demographics form, an Asthma Control Test (ACT), Patient Health Questionnaire 15 (PHQ-15), and a Perceived Stress Scale (PSS).

Results: Using validated scoring for Asthma Control Tests, we classified patients as well controlled (ACT score greater than or equal to 20) and not controlled (ACT score less than or equal to 19). Using SPSS software, chi-squared analysis indicated a significant association between PSS and ACT scores, PHQ-15 and ACT scores, and PSS and PHQ-15 scores. The analysis demonstrated a significant inverse relationship between PHQ-15 and ACT scores, and also between PSS and ACT scores, and a significant direct relationship between PSS and PHQ-15 scores. A statistically significant relative risk was found among moderate-to-high scores on PHQ-15, uncontrolled and moderate-to-high PSS scores, and uncontrolled asthma. A slight increase in relative risk in uncontrolled asthma was found in patients less than or equal to 50 years of age as compared to those older than 50 , and the relative risk of uncontrolled asthma was similar in women as compared to men.
\end{abstract}

Conclusion: The results of this study indicate an association between perceived stress, somatization, and uncontrolled asthma. These findings suggest the need to develop effective interventions in patients with asthma and comorbid stress and somatization.

\section{Background}

Asthma is a heterogeneous chronic airway disease impacting over 25 million adults in the United States, with annual direct and indirect costs of approximately $\$ 56$ billion dollars [1]. The pathogenesis of asthma is characterized by recurrent inflammation and repeated exacerbations over time that can be attributed to a wide variety of causes, commonly including environmental antigens, viruses, some medications, aspirin, and poor air quality [2-5]. Asthma is often present in patients with various comorbidities. The most frequently reported of these include rhinitis, sinusitis, gastroesophageal reflux disease, obstructive sleep apnea, hormonal disorders, and psychopathologies [6-10]. The presence of psychopathologies has been shown to increase the likelihood of poorly controlled asthma, either by affecting the diagnosis or assessment of control, influencing asthma phenotypes, or affecting the efficacy or adherence to therapy [11].
Numerous studies have documented poor asthma control and worse outcomes in patients with clinical depression and anxiety [12-16]. The Global Initiative for Asthma (GINA 2020) highlights anxiety and depression as being associated with worse asthma control and suggests clinicians help patients distinguish between anxiety and asthma symptoms. GINA

*Corresponding author: Nereida A. Parada, MD, John W. Demming Department of Medicine, Section of Pulmonary Disease, Critical Care, and Environmental Medicine, Tulane University, 1430 Tulane Ave, Box 8509 New Orleans, LA 70112, USA, Tel: (504)-988-6253

Accepted: December 29, 2020

Published online: December 31, 2020

Citation: Moore M, Duncan CD, Gonis A, et al. (2020) Uncontrolled Asthma is Associated with Comorbid Stress and Somatoform Symptoms. Ann Pulmonol 4(1):45-49 
also suggests that clinicians address anxiety and depression in order to achieve symptom control in the majority of their patients [17]. Studies stress the importance of identifying these comorbidities in patients with asthma, as they can negatively affect asthma control if left untreated $[18,19]$.

Chronic stress has been shown to manifest allergic diseases in susceptible individuals as well as complicate control of existing allergic diseases [20]. In one study, patients with anxiety and atopy were shown to have positive skin prick tests (SPTs) for antigens they previously tested negative for [21]. In addition, chronic stress has been shown to alter beta-adrenergic and glucocorticoid receptors gene expression, to change cytokine regulation, and to increase cortisol levels. Many of these same cytokines are often derived from mast cells, which have been shown to be involved in the pathogenesis of asthma [22]. All of these changes may impact development of asthma and allergy flairs, eventually altering therapy response [23,24].

The prevalence of somatization is estimated to be $5-7 \%$ of the general population and is an important topic due to its impact on healthcare utilization [25]. One well validated and commonly used tool to measure somatization is the PHQ 15 [26-28]. One study of 2091 primary care clinic patients found comorbid depression, anxiety, and somatization in roughly $50 \%$ of patients [29]. According to a study of 1456 patients, those with higher somatization scores had around twice the annual health care costs and around twice the outpatient and inpatient visits compared to those without somatization [30]. Additionally, a survey of 212 asthma patients found that those with anxiety, depressive, and somatoform disorders were at increased risk of asthma related emergency room visits [31].

The purpose of this study was to identify the associations between perceived stress, somatization, and perceived asthma control in patients with asthma. The patient centered and guideline-driven approach used in this study attempts to identify these associations among patients with asthma in an outpatient asthma center.

\section{Subjects and Methods}

Study participants were adult patients with a diagnosis of moderate to severe asthma who were receiving guideline driven outpatient care by a trained allergist and pulmonologist at the Tulane Asthma Center from May 2018 to December 2018. In total, there were 100 participants (76\% Female) with a mean age of 53.4 (SD \pm 14 ) and mean time with asthma of 26.1 years $(S D \pm 2.1$ ). All participants provided verbal informed consent prior to participation. Participants were then instructed to complete the following four self-administered questionnaires:

Demographic Data: A brief 3-question questionnaire including sex, age, and time since asthma diagnosis in years.

Asthma Control Test (ACT): Five questions, each scored on a 5-point Likert-type scale (ranging from 1-5), with a total score ranging from 5 (poor asthma control) to 25 (well controlled asthma). The questions measure self-perception of asthma's effect on activities of daily living, frequency of shortness of breath and other asthma symptoms, use of res- cue medications, and overall perception of asthma control during the previous 4 weeks.

Perceived Stress Scale (PSS): Ten questions, each scored on a 5-point Likert-type scale (ranging from 0-4), with a total score ranging from 0 (low stress) to 40 (high stress). The questions measure self-perception of frequency and severity of stressful events within one's life for the past 4 weeks. Questions include "How often have you been upset because something happened unexpectedly?", "How often have you felt that you were unable to control important things in your life?", " How often have you felt nervous and stressed?", "How often have you felt confident about your ability to handle your personal problems?", "How often have you felt that things were going your way?", "How often have you found that you could not cope with all the things that you had to do?", "How often have you been able to control irritations in your life?", "How often have you felt that you were on top of things?", "How often have you been angered because of things that were outside of your control?", and "How often have you felt difficulties were piling up so high that you could not overcome them?" [32].

Patient Health Questionnaire (PHQ-15): Fifteen questions, each scored on a 3-point Likert-type scale (ranging from 0-2), with a total score ranging from 0 (Minimal level of Somatic Symptom Severity) to 30 (High level of Somatic Symptom Severity). The questions measure self-perception of the prevalence and frequency of physical symptoms commonly associated with somatization. Symptoms included: stomach pain, back pain, extremity pain, menstrual cramps, headaches, chest pain, dizziness, fainting spells, heart racing, shortness of breath, pain/problems with sexual intercourse, constipation/loose bowels/diarrhea, nausea/gas/indigestion, low energy, and trouble sleeping [26-28].

The institutional review board at Tulane University approved the use of PSS, PHQ-15, and ACT surveys in clinical practice.

\section{Statistical Analysis}

All raw data from original paper questionnaires was entered into Excel and verified by two research assistants to check for transcribing errors. Overall, summative scores for individual ACT, PSS, and PHQ-15 questionnaires were calculated. Scores were then placed in stratified categories based on accepted validated guidelines. Categorical variables were then analyzed using Chi-Square, Spearman's Rho Correlation Coefficient, and relative risk using SPSS. Statistical significance was determined based on a $p$-value $<0.05$ or the values of a $95 \%$ confidence interval entirely being greater than one.

\section{Results}

Table 1 describes the 100 participants. The majority of the patients were women (76\%). The median age of the patients was 55 (range: $18-87$ ). The vast majority of patients (76\%) had a diagnosis of asthma greater than 5 years.

Table 2 assesses relative risk of uncontrolled asthma based on the clinical data elucidated in this study. Of the 100 patients in the study, 60 had uncontrolled asthma (ACT less than 
Citation: Moore M, Duncan CD, Gonis A, et al. (2020) Uncontrolled Asthma is Associated with Comorbid Stress and Somatoform Symptoms. Ann Pulmonol 4(1):45-49

Table 1: General demographic information for patients in this study.

\begin{tabular}{|l|l|l|l|l|l|l|}
\hline \multicolumn{2}{|l|}{ Sex } & Age & Time with Asthma & \\
\hline Male & Female & Prefer Not to Answer & Median: 55 & Greater Than 5 years & LessThan/Equal to 5 Years & Unanswered \\
\hline 21 & 76 & 3 & Range: 18-87 & 76 & 22 & 2 \\
\hline
\end{tabular}

Table 2: Relative risk of uncontrolled asthma based on demographics,stress scores, and somatization.

\begin{tabular}{|c|c|c|c|c|c|c|c|c|c|c|}
\hline & \multicolumn{2}{|l|}{ Sex } & \multicolumn{2}{|c|}{ Age (Years) } & \multicolumn{2}{|c|}{$\begin{array}{l}\text { Time with Asthma } \\
\text { (Years) }\end{array}$} & \multicolumn{2}{|c|}{$\begin{array}{l}\text { PHQ-15 Score } \\
\text { Category }\end{array}$} & \multicolumn{2}{|c|}{ PSS Score Category } \\
\hline & Male & Female & $>50$ & $<$ or $=50$ & $>5$ & $<$ or $=5$ & Mod to High & Low & Mod to High & Low \\
\hline Uncontrolled & 12 & 46 & 33 & 27 & 44 & 16 & 44 & 16 & 44 & 16 \\
\hline Controlled & 9 & 30 & 29 & 11 & 31 & 9 & 13 & 27 & 20 & 20 \\
\hline $\begin{array}{l}\text { Relative Risk of } \\
\text { U/C Asthma }\end{array}$ & \multicolumn{2}{|c|}{$\begin{array}{l}\text { If Female: } 1.06 \\
(95 \% \mathrm{Cl}: 0.70-1.60)\end{array}$} & \multicolumn{2}{|c|}{$\begin{array}{l}\text { If Age < or = 50: } 1.34 \\
\text { ( } 95 \% \mathrm{Cl}: 0.98-1.82)\end{array}$} & \multicolumn{2}{|c|}{$\begin{array}{l}\text { If time w/ asthma > } \\
\text { 5:1:09 (95\% Cl: } 0.77- \\
1.55)\end{array}$} & \multicolumn{2}{|c|}{$\begin{array}{l}\text { If Mod-High Score: } 2.75 \\
\text { (95\% Cl: } 1.62-4.68)\end{array}$} & \multicolumn{2}{|c|}{$\begin{array}{l}\text { If Mod-High Score: } 1.78 \\
\text { (95\% Cl: } 1.12-2.83)\end{array}$} \\
\hline
\end{tabular}

Table 3: Relative Risk of indivisual PHQ-15 symptom prevalence per ACT score category.

\begin{tabular}{|c|c|c|c|c|}
\hline Somatic Symptom & $\begin{array}{l}\text { Total\# w/ } \\
\text { Symptom }\end{array}$ & $\begin{array}{l}\text { \# w/ Uncontrolled } \\
\text { ACT Score }\end{array}$ & $\begin{array}{l}\text { \# 24w/ Controlled } \\
\text { ACT Score }\end{array}$ & Relative Risk of U/C Asthma \\
\hline Stomach pain & 49 & 36 & 13 & 2.00 (95\% Cl: 1.17-3.40) \\
\hline Back pain & 71 & 47 & 24 & 1.69 (99\% Cl: 1.07-2.67) \\
\hline Arm/Leg/Joint Pain & 72 & 48 & 24 & $1.78(95 \% \mathrm{Cl}: 1.13-2.79)$ \\
\hline Mentrual Pain & 13 & 6 & 7 & 0.76 (95\% Cl: 0.42-1.37) \\
\hline Headaches & 64 & 44 & 20 & 1.78 (95\% Cl: 1.12-2.83) \\
\hline Chest pain & 49 & 42 & 7 & 4.62 (95\% Cl: 2.26-9.44) \\
\hline Dizziness & 40 & 34 & 6 & 3.78 (95\% Cl: 1.75-8.16) \\
\hline Fainting & 15 & 12 & 3 & 2.20 (95\% Cl: 0.78-6.23) \\
\hline Heart pounding & 46 & 35 & 11 & 2.25 (95\% Cl: 1.27-3.98) \\
\hline Shortness of Breath & 79 & 57 & 22 & 3.23 (95\% Cl: $2.20-4.74)$ \\
\hline Pain with Sex & 14 & 10 & 4 & 1.51 (95\% Cl: 0.64-3.59) \\
\hline Constipation & 46 & 33 & 13 & 1.77 (95\% Cl: 1.04-3.01) \\
\hline Nausea/Gas & 62 & 45 & 17 & 2.27 (95\% Cl: 1.41-3.65) \\
\hline Tiredness / Low Energy & 81 & 56 & 25 & 2.60 (95\% Cl: 1.77-3.82) \\
\hline Trouble Sleeping & 68 & 50 & 18 & 2.68 (95\% Cl: 1.70-4.23) \\
\hline
\end{tabular}

or equal to 19) and 40 had controlled asthma (ACT greater than or equal to 20). The relative risk of uncontrolled asthma was similar in women as compared to men ( $R R=1.06 ; 95 \%$ confidence interval 0.70 to 1.60 ). There was a slight increase in relative risk in uncontrolled asthma in patients less than or equal to 50 years of age as compared to those older than 50 ; however this was not statistically significant $(R R=1.34$; 95\% confidence interval 0.98-1.82). Time since diagnosis of asthma had no association on asthma control (RR = 1.09; $95 \%$ confidence interval 0.77-1.55). A moderate to high score on the $\mathrm{PHQ}-15$ questionnaire had a higher relative risk of uncontrolled asthma as compared to participants with a minimal to low score $(\mathrm{RR}=2.75 ; 95 \% \mathrm{Cl}, 1.62-4.68)$. A moderate to high score on the PSS questionnaire had higher relative risk of uncontrolled asthma as compared to participants with a low score $(\mathrm{RR}=1.78 ; 95 \% \mathrm{Cl}, 1.12-2.83)$. Both of these validated questionnaire findings are statistically significant.

Table 3 delves further into the association of individual PHQ-15 symptoms and asthma control. Twelve of the fifteen symptoms in the PHQ-15 questionnaire showed an increased relative risk of uncontrolled asthma. These include stomach pain, back pain, arm/leg/joint pain, headaches, chest pain, dizziness, heart pounding, shortness of breath, constipation, nausea/gas/indigestion, tired/low energy, and trouble sleeping. The symptoms that were not statistically significantly associated were menstrual pain, fainting, and pain with sex. Relative risk of uncontrolled asthma for each of these symptoms can be found in Table 3 .

Table 4 further elucidates associations between ACT scores, PSS scores, and PHQ-15 scores. A significant association between ACT and PSS was observed $\left(\chi^{2}(2)=6.62\right.$, 
Citation: Moore M, Duncan CD, Gonis A, et al. (2020) Uncontrolled Asthma is Associated with Comorbid Stress and Somatoform Symptoms. Ann Pulmonol 4(1):45-49

Table 4: Associations of ACT, PSS, and PHQ-15 score categories: Raw data, Chi Square Analysis, Likelihood Ratio, and Spearman's Rho.

\begin{tabular}{|c|c|c|c|c|c|}
\hline & & \multicolumn{2}{|l|}{ ACT } & \multicolumn{2}{|l|}{ PSS } \\
\hline & & Controlled & Uncontrolled & High-Mod & Low \\
\hline \multirow[t]{2}{*}{ PSS } & High-Mod & 20 & 44 & & \\
\hline & Low & 20 & 16 & & \\
\hline \multirow[t]{2}{*}{ PHQ-15 } & High- Med & 13 & 44 & 44 & 13 \\
\hline & Low-Min & 27 & 16 & 20 & 33 \\
\hline ACT v.PSS & \multicolumn{5}{|c|}{$\begin{array}{l}\text { Pearsons Chi-Square: } 6.616 ; \mathrm{df}=2 . \text { Likelihood Ratio: } 6.787 ; \mathrm{df}=2 . \\
\text { Spearman's Rho }=0.26 . \mathrm{N} \text { valid cases }=100\end{array}$} \\
\hline ACT v.PHQ-15 & \multicolumn{5}{|c|}{$\begin{array}{l}\text { Pearsons Chi-Square: } 26.294 ; \mathrm{df}=3 . \text { Likelihood Ratio: } 29.152 ; \mathrm{df}=3 . \\
\text { Spearman's Rho }=0.502 . \mathrm{N} \text { valid cases }=100\end{array}$} \\
\hline PSS v.PHQ-15 & \multicolumn{5}{|c|}{$\begin{array}{l}\text { Pearsons Chi-Square: } 26.492 ; \mathrm{df}=6 . \text { Likelihood Ratio: } 29.388 ; \mathrm{df}=6 . \\
\text { Spearman's Rho }=0.47 . \mathrm{N} \text { valid cases }=100\end{array}$} \\
\hline
\end{tabular}

$\mathrm{p}<0.05 ;$ Spearman's Rho - 0.26). A significant association between ACT and PHQ-15 was observed $\left(\chi^{2}(3)=26.29, p<\right.$ 0.001 ; Spearman's Rho $=-0.502)$. A significant association between PSS and PHQ-15 was observed $\left(\chi^{2}(6)=26.49, p<0.001\right.$; Spearman's Rho $=0.47)$.

\section{Discussion}

This study shows that a clinically significant association exists between uncontrolled asthma, perceived stress, and psychosomatic symptoms. Significant relationships were found between ACT and PSS scores, ACT and PHQ-15 scores, and $\mathrm{PSS}$ and $\mathrm{PHQ}-15$ scores. The increased relative risk of uncontrolled asthma among participants with a moderate-to-high PSS score seen in this study reveals an association between increased anxiety and poorer outcomes for asthma patients. In regard to asthma control and somatization, patients showed an increased relative risk of uncontrolled asthma with both a cumulative moderate-to-high score on the PHQ-15 questionnaire and with high scores on a multitude of the individual PHQ-15 questions. The significant association between PSS and PHQ-15 scores is also notable.

Although previous studies have shown a relationship between female gender and more severe asthma symptoms, $[29,30]$ this study was unable to identify a significant association between gender and asthma. Specifically, female gender lacked a statistically significant increase in relative risk of uncontrolled asthma (RR: 1.06 [95\% Cl: 0.70-1.60]). Furthermore, neither age nor time since diagnosis had a statistically significant effect on asthma control in this study.

In light of the findings of both this study and prior research, it is clear that patient care teams need to assess for stress and psychosomatic symptoms in patients with asthma in order to properly address these conditions with personalized care. Some previous studies have approached interventions such as meditation, yoga, and breathing exercises. These studies did show improvement in overall quality of life without change in lung function [31,33]. A yoga breathing intervention study, involving twenty-minute sessions twice a day over three months, showed improvement in both quality of life and FEV1 [34]. Meditations have also been shown to improve lung function in patients with asthma [35]. To further clarify the effects of breathing and relaxation interventions, future prospective studies need to focus on lung physiology, inflammation, stress assessment, presence of somatization symptoms, and asthma control.

A number of limitations exist for this six-month study. This study does not include any clinical data, pulmonary physiology data, or inflammation data, as it focused on the assessment of asthma control and validated questionnaires for stress and somatization. Assessment of asthma control, stress, and somatic symptoms are subjective measures. This study included one fall allergy season, and only included patients in the Greater New Orleans area. In addition, this study did not collect information on whether ethnicity and socioeconomic class may affect somatic symptom severity [36-38].

\section{Conclusion}

This study shows a significant association between uncontrolled asthma, higher levels of perceived stress, and an increased incidence of somatic symptoms among patients with asthma. These results reinforce the need for assessment of stress and somatic symptoms in asthma patients, and reveal new research opportunities aimed at analyzing the possible benefits of stress and psychosomatic symptom management treatments in improving asthma control. Future prospective studies would benefit from investigating how these symptoms change with effective interventions.

\section{References}

1. Centers for Disease Control and Prevention (2018) Most recent asthma data | CDC. National Data.

2. Sergel, Michelle J, Cydulka, et al. (2009) Asthma. In: Wolfson Allan B, Harwood-Nuss Ann, Harwood-Nuss' clinical practice of emergency medicine. ( $5^{\text {th }}$ edn), Lippincott Williams \& Wilkins.

3. Subbarao P, Sears MR (2018) Identifying and preventing the progression of asthma to chronic obstructive pulmonary disease. Personalizing Asthma Management for the Clinician, 179190.

4. Bains S (2012) Acute exacerbations of asthma. Clinical focus series: Acute exacerbation of respiratory diseases, 17-36. 
Citation: Moore M, Duncan CD, Gonis A, et al. (2020) Uncontrolled Asthma is Associated with Comorbid Stress and Somatoform Symptoms. Ann Pulmonol 4(1):45-49

5. Papi A, Brightling C, Pedersen SE, et al. (2018) Asthma. Lancet 391: 783-800.

6. Ledford DK, Lockey RF (2013) Asthma and comorbidities. Curr Opin Allergy Clin Immunol 13: 78-86.

7. Bisaccioni C, Aun MV, Cajuela E, et al. (2009) Comorbidities in severe asthma: Frequency of rhinitis, nasal polyposis, gastroesophageal reflux disease, vocal cord dysfunction and bronchiectasis. Clinics (Sao Paulo) 64: 769-773.

8. Abdul Razak MR, Chirakalwasan N (2016) Obstructive sleep apnea and asthma. Asian Pac J Allergy Immunol 34: 265-271.

9. Yung JA, Fuseini H, Newcomb DC (2018) Hormones, sex, and asthma. Ann Allergy Asthma Immunol 120: 488-494.

10. Kelly K, Ratliff S, Mezuk B (2019) Allergies, asthma, and psychopathology in a nationally-representative US sample. J Affect Disord 251: 130-135.

11. Boulet LP, Boulay ME (2011) Asthma-related comorbidities. Expert Rev Respir Med 5: 377-393.

12. Denton E, Bondarenko J, Tay T, et al. (2018) Factors associated with dysfunctional breathing in patients with difficult to treat asthma. J Allergy Clin Immunol Pract 7: 1471-1476.

13. Liu S, Wu R, Li L, et al. (2014) The prevalence of anxiety and depression in chinese asthma patients. PLoS One.

14. Ciprandi G, Schiavetti I, Rindone E, et al. (2015) The Impact of anxiety and depression on outpatients with asthma. Ann Allergy Asthma Immunol 115: 408-414.

15. Gade E, Khan DA, DeFina LF, et al. (2014) The relationship between asthma and self-reported anxiety in a predominantly healthy adult population. Ann Allergy Asthma Immunol 112: 329-332.

16. Rod NH, Kristensen TS, Lange P, et al. (2012) Perceived stress and risk of adult-onset asthma and other atopic disorders: A longitudinal cohort study. Allergy 67: 1408-1414.

17. Global Initiative for Asthma (2020) Global strategy for asthma management and prevention.

18. Del Giacco SR, Cappai A, Gambula L, et al. (2016) The asthma-anxiety connection. Respir Med 120: 44-53.

19. Parry GD, Cooper CL, Moore JM, et al. (2012) Cognitive behavioural intervention for adults with anxiety complications of asthma: prospective randomised trial. Respir Med 106: 802-810.

20. Dave ND, Xiang L, Rehm KE, et al. (2011) Stress and allergic diseases. Immunol Allergy Clin North Am 31: 55-68.

21. Heffner KL, Kiecolt-Glaser JK, Glaser R, et al. (2014) Stress and anxiety effects on positive skin test responses in young adults with allergic rhinitis. Ann Allergy Asthma Immunol 113: 13-18.

22. Theoharides TC, Enakuaa S, Sismanopoulos N, et al. (2012) Contribution of stress to asthma worsening through mast cell activation. Ann Allergy Asthma Immunol 109: 14-19.
23. Patterson AM, Yildiz VO, Klatt MD, et al. (2014) Perceived stress predicts allergy flares. Ann Allergy Asthma Immunol. 112: 317321.

24. Barnthouse M, Jones BL (2019) The impact of environmental chronic and toxic stress on asthma. Clin Rev Allergy Immunol 57: 427-438.

25. Pilipenko N, Karekla M, Georgiou A, et al. (2016) Impact of psychiatric illness upon asthma patients' health care utilization and illness control. Are all psychiatric comorbidities created equal? Psychol Health Med 21: 787-799.

26. Toussaint A, Kroenke K, Baye F, et al. (2017) Comparing the patient health questionnaire - 15 and the Somatic Symptom Scale -8 as measures of somatic symptom burden. J Psychosom Res 101: 44-50.

27. Kroenke K, Spitzer RL, Williams JB, et al. (2010) The patient health questionnaire somatic, anxiety, and depressive symptom scales: A systematic review. Gen Hosp Psychiatry 32: 345-359.

28. Barsky AJ, Orav EJ, Bates DW (2005) Somatization increases medical utilization and costs independent of psychiatric and medical comorbidity. Arch Gen Psychiatry 62: 903-910.

29. Löwe B, Spitzer RL, Williams JBW, et al. (2008) Depression, anxiety and somatization in primary care: Syndrome overlap and functional impairment. Gen Hosp Psychiatry 30: 191-199.

30. Loeb TB, Joseph NT, Wyatt GE, et al. (2018) Predictors of somatic symptom severity: The role of cumulative history of trauma and adversity in a diverse community sample. Psychol Trauma 10: 491-498.

31. Huntley A, White AR, Ernst E (2002) Relaxation therapies for asthma: A systematic review. Thorax 57: 127-131.

32. Cohen S, Kamarck T, Mermelstein R (1983) A global measure of perceived stress. J Health Soc Behav 24: 385-396.

33. Thomas M, McKinley RK, Mellor S, et al. (2009) Breathing exercises for asthma: A randomised controlled trial. Thorax 64: 5561.

34. Yang ZY, Hui-Bin Zhong, Chen Mao, et al. (2016) Yoga for asthma. Cochrane Database Syst Rev.

35. Paudyal P, Jones C, Grindey C, et al. (2018) Meditation for asthma: Systematic review and meta-analysis. J Asthma 55: 771-778.

36. Hinz A, Ernst J, Glaesmer H, et al. (2017) Frequency of somatic symptoms in the general population: normative values for the patient health questionnaire-15 (PHQ-15). J Psychosom Res 96: 27-31.

37. Saxena T, Saxena M (2009) The effect of various breathing exercises (pranayama) in patients with bronchial asthma of mild to moderate severity. Int J Yoga 2: 22-25.

38. Vasquez JC, Fritz GK, Kopel SJ, et al. (2009) Ethnic differences in somatic symptom reporting in children with asthma and their parents. J Am Acad Child Adolesc Psychiatry 48: 855-863.

DOI: $10.36959 / 918 / 451$

Copyright: (C) 2021 Moore M, et al. This is an open-access article distributed under the terms of the Creative Commons Attribution License, which permits unrestricted use, distribution, and reproduction in any medium, provided the original author and source are credited. 